\title{
Dilemas ambientais
}

\section{e fronteiras do conhecimento}

\author{
PEDRO ROBERTO JACOBI ${ }^{I}$ \\ e LEANDRO LUIZ GIATTI ${ }^{I I}$
}

A

S SOCIEDADES contemporâneas se caracterizam por um quadro socioambiental onde alterações profundas e impactos ambientais decorrem por meio de relações complexas, quantitativas e qualitativas. Os sistemas socioambientais, sejam eles representados por cidades, países, bacias hidrográficas, biomas, cadeias produtivas, sejam por mercados de commodities, não são sistemas fechados, pelo contrário, possuem dinâmicas de intensificação de suas interações temporais e espaciais, implicando crescentes graus de interdependência, que, por sua vez, exacerbam as fragilidades dos sistemas de suporte à vida, ao passo que se caracterizam em ameaças crescentes dados os contextos de vulnerabilidade e injustiças ambientais. A perspectiva de contingenciamentos e de gestão com foco em produção de alimentos, consumo exacerbado, disponibilidade, uso e conservação de recursos hídricos e produção e uso de energia implica nexos de compensações e desequilíbrios que colocam respectivos campos de intervenção e gestão como elementos indissociáveis na busca pela sustentabilidade. Nunca foi tão evidente o grau em que os distintos tipos de escassez se colocam em condição definitivamente intrínseca.

Por sua vez, a fenomenologia inerente ao fluxo de capital e ao mercado financeiro, com sua fluidez exacerbada, conjumina velocidade e força de mudanças que interpõem as alternativas convencionais de governabilidade com foco na conservação e na integridade dos ecossistemas. Tanto quanto se torna cada vez mais premente o reconhecimento da complexidade que implica a sustentabilidade, como, do mesmo modo, se exigem a produção e a aplicação de saberes interdisciplinares em sinergia, comprometidos com o tecido conjunto das dimensões interconectadas dos sistemas socioambientais.

Os fenômenos emergentes com elevados graus de incertezas e desdobramentos ampliados dão o tom e a magnitude da necessária associação entre sustentabilidade, adaptação e resiliência. As dinâmicas intercontinentais e fluidas das forças motrizes que disseminam a degradação e pulverizam as inequidades fundamentam o clamor pela governança global. A interdependência que reside em tudo o que é tangível enquanto medida de contingenciamento conduz ao reconhecimento da busca pelo equilíbrio entre ações. A conectividade, a diminuição do mundo por meio da massificação e da produção em larga escala e a perspectiva de ações para a sustentabilidade, como fenômenos que aproximam 
o indivíduo das questões globais, fazem sobrelevar a importância do direito à informação, o dever da corresponsabilização e, conjuntamente, o direito e o dever da participação social nas decisões e nas políticas. Por sua vez, a dissolução das certezas coloca como necessária a tomada de decisão baseada naquilo que é incerto e, consequentemente, na busca por decisões e na democratização de saberes, incluindo-se a perspectiva de um relacionamento crítico entre a sociedade e a produção de saberes científicos essenciais à tomada de decisões. De modo emblemático, grande expressão quanto às dúvidas futuras se caracteriza com o fenômeno global das mudanças climáticas e suas escalas diferenciadas de complexidades em cadeias de causas, consequências e vulnerabilidades.

Todavia, apesar de décadas de crítica e de novas epistemologias, ao passo que se ressalta o imperativo da complexidade e das incertezas sistêmicas, ainda é marcante a necessidade de se ampliar o diálogo entre ciência, sociedade e tomada de decisões. Quanto a isso, notória ainda é a prevalência de uma racionalidade cognitivo-instrumental que tem agravado a situação ambiental do planeta, mantendo uma relação abissal tanto quanto às desigualdades materiais como no que se refere à diversidade de saberes.

Os mais relevantes problemas que afetam o nosso planeta são de natureza global e suas causas não podem restringir-se apenas aos fatores estritamente físicos ou biológicos, pois ensejam dimensões políticas, econômicas, institucionais, sociais e culturais. O desafio da interdisciplinaridade precisa ser visto como um processo de conhecimento que busca estabelecer cortes transversais na compreensão e na forma de se produzir explicações, concretizando severas mudanças em processos de aprendizagem social e, por sua vez, de intervenção na realidade.

A exemplificar situações relevantes, observa-se que sofisticado desenvolvimento técnico-científico pressiona quanto a produção e consumo de alimentos industrializados, os quais podem representar profundas mudanças nutricionais e significativos impactos ambientais. Por outro lado, um também sofisticado aparato científico mais comprometido com a saúde pública e com a sustentabilidade vem produzir inúmeros argumentos indicando que uma alimentação mais natural, de manipulação caseira, com gêneros sazonais e produção proximal aos mercados de consumo, contribui, conjuntamente, para a saúde e para o modo como são empregados os recursos naturais nas cadeias produtivas. Outra situação digna de nota coloca-se quanto à multidimensionalidade da vulnerabilidade a desastres associáveis às mudanças climáticas. Nesse campo, enfatiza-se a necessidade de se romper com a hegemonia de medidas técnico-científicas para a busca de abordagens mais holísticas, que incorporem inclusive aspectos sócio-históricos das áreas de risco e saberes específicos forjados na complexidade local.

É irrefutável a evidência de que não há mais apenas uma ciência e uma resposta mediante os problemas socioambientais contemporâneos. É fundamental promover o protagonismo entre os saberes, e não apenas saberes científicos. Re- 
mete-se à necessidade de se decidir quanto aos aparatos científicos e os saberes disponíveis que são relevantes para cada situação. E a decisão quanto a isso deve ser constantemente alicerçada em processos de participação de todas as partes interessadas (stakeholders). Essa condição não se coloca como uma ruptura com os modos mais tradicionais e especializados de se produzir ciência. De fato, esse é um imperativo de se clamar por processos mais democráticos superando a convencional relação da sociedade com a ciência, que até então se baseava na confiança quanto aos enunciados científicos. Assim, torna-se essencial o foco nas incertezas, pautando decisões que dependem sim da produção da ciência tradicional (ou seja, denominada como ciência normal por Thomas Kuhn, considerando sua estrutura de validação por pares especializados), porém permitindo a ampliação da comunidade de pares, de interessados ou sujeitos dos riscos, em que se configurem estruturas de governança de natureza pós-normal.

Diante desses dilemas, buscando identificar desafios contemporâneos ao conhecimento e às ações inerentes, busca-se, com a proposição deste volume de Estudos Avançados, dialogar com: questões de interdisciplinaridade; nexos de sustentabilidade; fenômenos emergentes, complexidade e incertezas; o contemporâneo aprofundamento das iniquidades; consumo, alimentação e sustentabilidade; e as relações entre as ciências, os saberes e as políticas.

I Instituto de Energia e Ambiente/Procam, Universidade de São Paulo, São Paulo/São Paulo, Brasil.

${ }^{\text {II }}$ Faculdade de Saúde Pública, Universidade de São Paulo, São Paulo/São Paulo, Brasil. 